\title{
Effect of bonding agent production materials on the mechanical properties of composite solid rocket propellant
}

\author{
Ali.M.Abd elall ${ }^{*}$, and Guo Lin \\ Beihang University, Beijing, China
}

\begin{abstract}
An effective pathway was explored to design and select proper bonding agents that could effectively improve the interfacial interactions between bonding agents and solid particles, modern types of composite solid propellants focused on increasing the mechanical properties in order to withstand stresses produced due to various loading conditions, changes in environmental condition, transportation and handling. In this work, the study show that the effect of solvent in production of bonding agent has a different impact on the mechanical properties as the polar solvent in formulation $\mathrm{S}_{3}$ has a good strain values corresponding to the stress. Also the changing of the percentage of $\mathrm{CuCl}_{2}$ has a significant effect on mechanical properties as giving high value of strain with the percentage of $4.5 \%$ and returns back the value of strain decrease with increase the percentage of $\mathrm{CuCl}_{2}$ to give the lowest values of the strain corresponding to the stress value with percentage $7.5 \%$.
\end{abstract}

\section{Introduction}

As the requirements for solid rocket motors become more challenging to achieve, a growing need exists to push the properties of solid composite propellants to levels previously thought unattainable. These increasing demands can mainly be achieved by modifying the composition of the propellant since the physical parameters of the motor limited by current materials technology. Traditionally, enhanced propellant properties are attained through incorporation of additives in small concentrations to the propellant formulation [1-3]. A bonding agent is added to the propellant formulation to improve the interaction between the solid particles and binder matrix and ameliorate mechanical properties of propellants [4-8]. These bonding agents contain functional groups that can both interact with the solid filling materials and react with the binder system and can thus enhance the integration between the solid filling materials and binder matrix of composite solid propellants [9-10]. Bonding agents usually used in composite solid propellants are aziridine and its derivatives, polyamine and its derivatives, alkanolamine and its derivatives, titanate compounds, boric-acid-ester bonding agents, organo-functional silanes, hydantoin compounds, compounds containing ferrocenyl functions, neutral polymeric bonding agents, oxadiazoline derivatives, etc. [11-13]. The aziridine polyester component of the bonding

*Corresponding author: aliabdelall43@yahoo.com 
agent system is, as indicated, the reaction product of an aziridinyl phosphine oxide with a polycarboxylic acid. It's used to bond the solid ingredients in the matrix to prevent their settling down and increase the cohesion force between the binder and the solids. One of the commonly used bonding agents is methyl aziridnyl phosphineoxide (MAPO) hydrogen bond are formed between molecules of MAPO and that of AP and polyurethane binder chains also with $\mathrm{OH}$ terminal groups of HTPB. Hence a network is formed inside the polymeric matrix which prevents settling of solid ingredients. Bonding agents represent the base of propellant stability during aging [6]. Some examples for the bonding agents as methyl aziridinyl phosphineoxide (MAPO) and (MAT-4) which is produced from the reaction of 2 moles methyl aziridinyl phosphineoxide (MAPO) plus 0.7 mole adipic acid and 0.3 mole tartaric acid as in equation (1) (14).

$$
\mathrm{MAPO}+\text { adipic acid }+ \text { tartaric acid } \longrightarrow\left(\text { MAT-4) }+\mathrm{n} \mathrm{H}_{2} \mathrm{O}\right.
$$

Many authors have studied the effect of bonding agents on the mechanical behavior of composite propellants. In this work, studies the effect of production materials of bonding agent on the mechanical properties of composite solid propellant.

\section{Experimental}

\subsection{Preparations of bonding agent samples and product tests evaluation}

Preparation of bonging agent samples is act like that the first three samples prepared with changing the solvent firstly toluene, acetone and methanol then taking symbols $\mathrm{S}_{1}, \mathrm{~S}_{2}$ and $\mathrm{S}_{3}$ respectively in order, secondly changing the percentage of initiator copper chloride $\mathrm{CuCl}_{2} 1 \%, 2 \%, 3 \%, 4 \%$ and $5 \%$ (weight percentage) then taking symbols $\mathrm{I}_{1}, \mathrm{I}_{2}, \mathrm{I}_{3}, \mathrm{I}_{4}$ and $\mathrm{I}_{5}$ respectively in order. MAPO (186.2 g) was dissolved in solvent $(500 \mathrm{ml})$ and the initiator placed in a three neck flask with a reflux device. The solution was stirred and heated in a water bath and heated to $55^{\circ} \mathrm{C}$ for $5 \mathrm{~h}$ with the slow addition of adipic acid $(44.3 \mathrm{~g})$ and tartaric acid $(19.5 \mathrm{~g})$ solution in $(1200 \mathrm{ml})$ solvent through a constant dropping funnel. After reaction, solvent was removed by vacuum distillation. Then $\mathrm{MAT}_{4}$ was obtained by vacuum drying at $60^{\circ} \mathrm{C}$. After production of bonding agent samples some tests were carried on as the aziridine content and the refractive index and listed results in tables to evaluate.

\subsection{Preparations of composite rocket propellant formulations}

Casting technique was employed for preparation of the 8 composite propellant formulations. The binder used in this work was HTPB pre polymer of $0.85 \mathrm{mg}$ equivalent $\mathrm{OH} / \mathrm{g}$ HTPB with DOZ as plasticizer and MAT4 as bonding agent. The pre polymer, bonding agent and the plasticizer were mixed together at $50-60^{\circ} \mathrm{C}$ then solid ingredients were added in portions and thoroughly mixing was continued for 30 minutes. At the end of mixing process, the curing agent HMDI of $11.9 \mathrm{mg}$ equivalent $\mathrm{NCO} / \mathrm{g}$ HMDI was added by certain amount which keeps the $\mathrm{NCO} / \mathrm{OH}$ ratio as 0.7 and mixing was carried out for relatively short time. Special degassing unit was employed to get rid of any air bubbles before slurry casting in special moulds for different measurements. Finally, the prepared formulations were cured at about $60^{\circ} \mathrm{C}$ for two weeks (15). The main constituents of the prepared reduced smoke composite propellants formulations are listed in table (1) in weight percentage.

Table 1. Compositions of the prepared composite propellant formulations based on PU binder.

\begin{tabular}{|c|c|c|c|c|c|}
\hline Formulation & AP & Al & Binder & solvent & $\mathbf{C u C l}_{\mathbf{2}} \mathbf{\%}$ \\
\hline $\mathrm{S}_{1}$ & 69 & 17 & 14 & Toluene & 3 \\
\hline $\mathrm{S}_{2}$ & 69 & 17 & 14 & Acetone & 3 \\
\hline
\end{tabular}




\begin{tabular}{|c|c|c|c|c|c|}
\hline $\mathrm{S}_{3}$ & 69 & 17 & 14 & Methanol & 3 \\
\hline $\mathrm{I}_{1}$ & 69 & 17 & 14 & Methanol & 1.5 \\
\hline $\mathrm{I}_{2}$ & 69 & 17 & 14 & Methanol & 3 \\
\hline $\mathrm{I}_{3}$ & 69 & 17 & 14 & Methanol & 4.5 \\
\hline $\mathrm{I}_{4}$ & 69 & 17 & 14 & Methanol & 6 \\
\hline $\mathrm{I}_{5}$ & 69 & 17 & 14 & Methanol & 7.5 \\
\hline
\end{tabular}

\subsection{Measurement of the aziridine content and the refractive index}

For determine the aziridine content of the bonding agent prepared samples, samples and the blank for each sample were prepared and then add the indicators and titrate with $\mathrm{KOH}$ in methanol $0.1 \mathrm{~N}$ until the color change and then the following equitation (2) is used.

Aziridine content $=\left(\left(\mathrm{V}_{\mathrm{B}}-\mathrm{V}_{\mathrm{S}}\right) * \mathrm{~N}_{\mathrm{KOH}} * 5.71\right) / \mathrm{wt}$

where: $V_{B} \ldots$ Volume of blank sample, $V_{S} \ldots$ Volume of $M_{A T}$ sample, wt......weight of $\mathrm{MAT}_{4}$ sample.

For determine the refractive index for the bonding agents' samples, refractometer device (Refractive Index ASTM D542) was used for each bonding agent prepared samples at $25^{\circ} \mathrm{C}$. A small drop of contacting liquid is placed on the center of the prism, and then the test sample is placed on the prism. The light source, index arm, and compensator drum are adjusted to align the sample through the eyepiece. The refractometer will then provide a digital read-out of the refractive index.

\subsection{Measurement of bonding agent viscosity}

The device for measuring viscosity is called as viscosimeter and a model of (Brookfield LVDII +Pro) which is digital and computer controlled. It can be fully controlled from the computer with its special software, first of all, an amount of $16 \mathrm{ml}$ bonding agent sample is needed for tests and then the device is turned on after adjusting the desired temperature, and then determined the viscosity of the bonding agent samples measured in centipoises (cp).

\subsection{Measurement of mechanical properties}

Stress-strain characteristics were measured experimentally for all the prepared samples by employing the ZWICK (model 1487) materials testing machine and the hardness shore (A) was measured using the hardness tester ZWICK (model 3102 ) at $25^{\circ} \mathrm{C}$. Five samples were tested for each prepared formulation and then the mean values of the obtained results were recorded.

\section{Results}

\subsection{Results of the aziridine content and the refractive index}

The results of the refractive index obtained from test act as a finger print to the obtained sample and for the aziridine content show that clear that the value of aziridine content increase with changing the solvent types ascending from $\left(\mathrm{S}_{1}\right)$ passing with $\left(\mathrm{S}_{2}\right)$ to $\left(\mathrm{S}_{3}\right)$ as increase in the more polar the solvent used in the reaction, the better the solvation and separation of the ions, as the rate of initiation and propagation is faster in more polar solvents. As in the solution polymerization a suitable solvent increase the capability for convective movement or stirring of the reactants reduces exotherm problem. The ability of 
media to carried higher charge of radicals the easier to find the reactants each other inside the solvent.

Table 2. Results of the aziridine content and the refractive index.

\begin{tabular}{|c|c|c|}
\hline Formulation & aziridine content \% & Refractive index \\
\hline $\mathrm{S}_{1}$ & 37.8 & 1.4785 \\
\hline $\mathrm{S}_{2}$ & 26.8 & 1.4865 \\
\hline $\mathrm{S}_{3}$ & 32.24 & 1.4873 \\
\hline $\mathrm{I}_{1}$ & 44.7 & 1.4689 \\
\hline $\mathrm{I}_{2}$ & 32.24 & 1.4873 \\
\hline $\mathrm{I}_{3}$ & 26.8 & 1.4865 \\
\hline $\mathrm{I}_{4}$ & 18.57 & 1.4663 \\
\hline $\mathrm{I}_{5}$ & 13.1 & 1.4604 \\
\hline
\end{tabular}

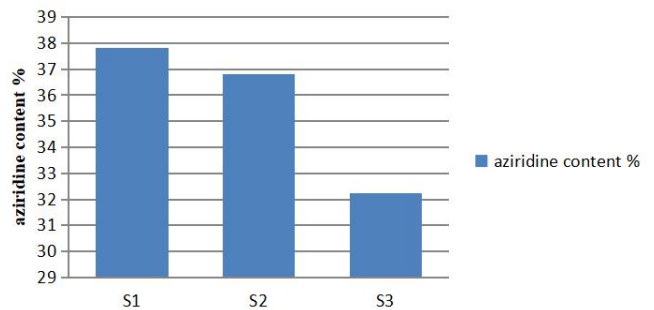

Fig. 1. Effect of different solvent on aziridine content $\%$.

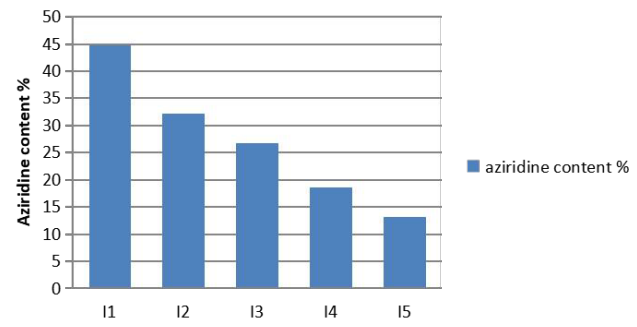

Fig. 2. Effect of $\mathrm{CuCl}_{2}$ percentage on aziridine content $\%$.

Also clear that the value of aziridine content decrease with changing the percentage of the initiator ascending from $\left(\mathrm{I}_{1}\right)$ passing with $\left(\mathrm{I}_{2}\right),\left(\mathrm{I}_{3}\right)$, and $\left(\mathrm{I}_{4}\right)$ to $\left(\mathrm{I}_{5}\right)$ as the reaction occurs much faster with a suitable cation source. In these systems the $\mathrm{CuCl}_{2}$ is referred to as a coinitiator while the cation source is the initiator. Upon reaction of the initiator with the coinitiator, an intermediate complex is formed which then goes on to react with the monomer unit. The more of the $\mathrm{CuCl}_{2}$ percentage is the more of cation source and the more of opining the aziridine ring and the lower of aziridine content which illustrated in table (2) and figure (1\&2).

\subsection{Viscosity of bonding agent samples}

The determination of viscosity for the prepared bonding agent (viscous copolymer product) samples using solution polymerization method was an essential step to ensure the relation between the molecular weight, chain length and the viscosity of (MAT-4 copolymer) as a result of the effect percentage of the initiator and solvent on the viscosity of the prepared samples illustrated in table (3), it is clear from the results that the prepared bonding agent viscosity reflected the degree of polymerization and also the chain length and the molecular weight, as the more polar of solvent gives higher opportunity for the polymerization to occur as in formulation $\mathrm{S}_{3}$. Also the percentage of initiator increased the more degree of polymerization and higher opportunity for opining the aziridine ring and attaching with the carboxylic acids increased and that has exactly great impact on the viscosity as the beginning with the low percentage of $\mathrm{CuCl}_{2}$ the viscosity began to increase slightly as in $\mathrm{I}_{1}$ passing to the highest value in $\mathrm{I}_{3}$ represented highest molecular weight then viscosity become again to decrease until reach $\mathrm{I}_{5}$ as the degree of polymerization increased and the number of the formed chain increased but its length decreased so viscosity decreased again. 
Table 3. Results of viscosity for bonding agent prepared samples.

\begin{tabular}{|c|c|}
\hline Formulation & Viscosity(cp) \\
\hline $\mathrm{S}_{1}$ & 13600 \\
\hline $\mathrm{S}_{2}$ & 25578 \\
\hline $\mathrm{S}_{3}$ & 41900 \\
\hline $\mathrm{I}_{1}$ & 23452 \\
\hline $\mathrm{I}_{2}$ & 41900 \\
\hline $\mathrm{I}_{3}$ & 52341 \\
\hline $\mathrm{I}_{4}$ & 28156 \\
\hline $\mathrm{I}_{5}$ & 12195 \\
\hline
\end{tabular}

\subsection{Mechanical properties of propellant samples}

The determination of mechanical properties for composite propellant formulations was essential step to ensure the capability of such propellant families to withstand the expected both thermal and mechanical loading through the storage and combustion process. The mechanical properties of tested propellant samples were carried out at $25{ }^{\circ} \mathrm{C}$. Table (4) shows the main parameters of the measured mechanical properties. Determination of the shore (hardness $\mathrm{A}_{0}$ ) is very important step to ensure that the propellant was completely cured then the cured propellant becomes ready to carry out the mechanical testes.

Table 4. Stress-strain characteristics of different propellant formulations at $25{ }^{\circ} \mathrm{C}$.

\begin{tabular}{|c|c|c|c|c|}
\hline Formulation & $\boldsymbol{\sigma}\left(\mathbf{k g} / \mathbf{c m}^{\mathbf{2}}\right)$ & $\mathbf{G ~ ( \% )}$ & $\mathbf{E}_{\mathbf{0}}\left(\mathbf{k g} / \mathbf{c m}^{\mathbf{2}}\right)$ & $\mathbf{A}_{\mathbf{0}}$ \\
\hline $\mathrm{S}_{1}$ & 6.1 & 27.1 & 28.36 & 59 \\
\hline $\mathrm{S}_{2}$ & 6.29 & 33.6 & 27.42 & 58 \\
\hline $\mathrm{S}_{3}$ & 6.43 & 47.4 & 24.45 & 55 \\
\hline $\mathrm{I}_{1}$ & 5.73 & 28.8 & 26.51 & 57 \\
\hline $\mathrm{I}_{2}$ & 6.43 & 47.4 & 24.45 & 55 \\
\hline $\mathrm{I}_{3}$ & 6.31 & 52.8 & 20.36 & 49 \\
\hline $\mathrm{I}_{4}$ & 6.03 & 35.9 & 23.69 & 52 \\
\hline $\mathrm{I}_{5}$ & 5.60 & 24.9 & 31.69 & 60 \\
\hline
\end{tabular}

\section{$\sigma(\mathrm{kg} / \mathrm{cm} 2)$}
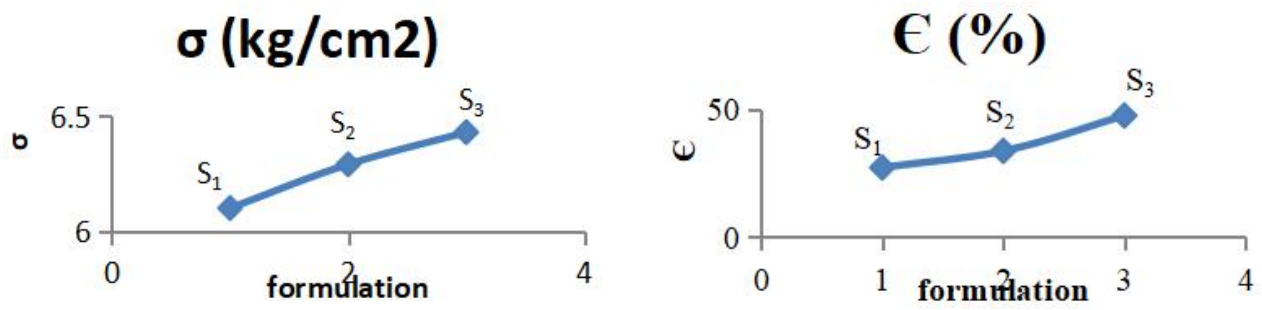

Fig. 3 (a\&b). Effect of different solvent on stress and strain.

\section{$\mathrm{EO}\left(\mathrm{kg} / \mathrm{cm}^{2}\right)$}

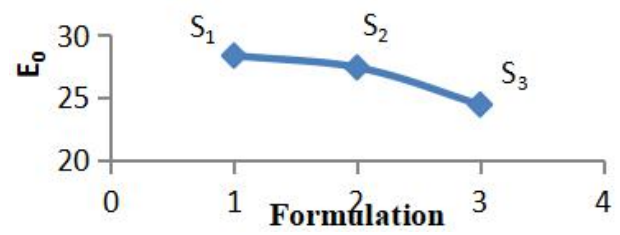

A0

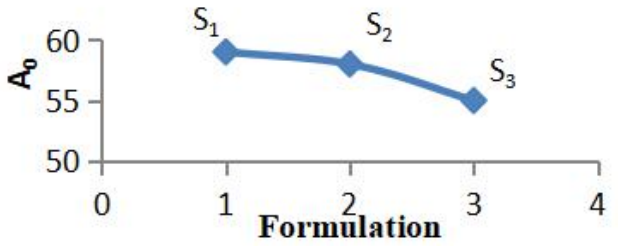

Fig. 4 (a\&b): Effect of different solvent on Young's modulus and hardness. 
According to the results tabulated in table (4) and figures $3(a \& b)$ and $4(a \& b)$ the mechanical properties of propellant formulations $S_{1}$ and $S_{2}$ are less values in strength $(\sigma)$, maximum strain (E) compared with propellant formulation $\mathrm{S}_{3}$ based on methanol in bonding agent production which gives good results for the propellant maximum strength $(\sigma)$, maximum strain $(\mathrm{C})$, young's modulus $\left(\mathrm{E}_{0}\right)$ and hardness $\left(\mathrm{A}_{0}\right)$ as $\mathrm{S}_{3}$ has a suitable bonding agent chain length gives high strain with acceptable stress.

\section{$\sigma\left(\mathrm{kg} / \mathrm{cm}^{2}\right)$}

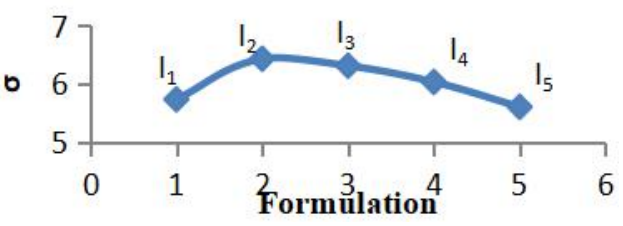

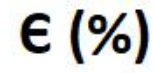

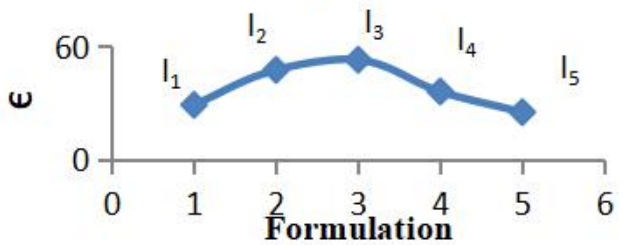

Fig. 5 (a\&b). Effect of different percentage of $\mathrm{CuCl}_{2}$ on stress and strain.

\section{$\mathrm{EO}\left(\mathrm{kg} / \mathrm{cm}^{2}\right)$}

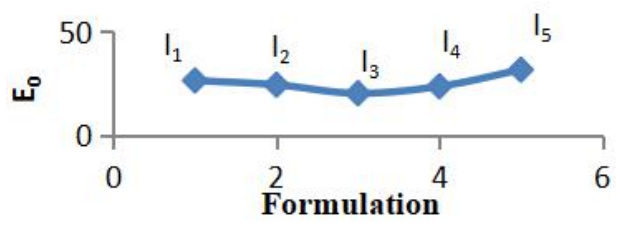

A0

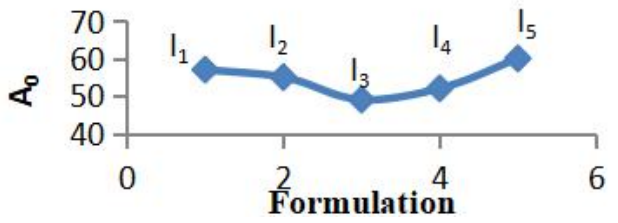

Fig. $6(\mathbf{a \& b})$. Effect of different percentage of $\mathrm{CuCl}_{2}$ on Young's modulus and hardness.

Also clear that from the figures $5(\mathrm{a} \& \mathrm{~b})$ and $6(\mathrm{a} \& \mathrm{~b})$ The propellant formulations based on different percentage in $\mathrm{CuCl}_{2}\left(\mathrm{I}_{1}, \mathrm{I}_{2}, \mathrm{I}_{3}, \mathrm{I}_{4}\right.$ and $\left.\mathrm{I}_{5}\right)$ show that first poor mechanical properties of stress $(\sigma)$, strain $(\mathcal{C})$ for $\mathrm{I}_{1}$ the low percentage of initiator due to low degree of polymerization of the bonding agent then it became higher in formulations $I_{2}$ and $I_{3}$ then the values of strength $(\sigma)$, maximum strain $(C)$ became lower again of $I_{4}$ and $I_{5}$ as the degree of polymerization increase of the bonding agent give short chain product as mention in the viscosity values of prepared copolymer (bonding agent MAT-4) samples.

\section{Conclusion}

The following conclusions are drawn from the present study which represents an approach for explaining the role of the bonding agents effecting on CSRP as the use of bonding agents in a very small percentage is essential for achieving the desired mechanical properties, and also for inhibiting the self-decomposition of the prepared propellant samples. The laboratory has a great role in preparing bonding agent (MAT4) and study how to improve the propellants' mechanical properties. Also show that the choosing of the suitable solvent in preparing bonding agent that gives better impact on the mechanical properties of the composite solid rocket propellant. As the strain corresponding to maximum stress depends on the used bonding agents MAT4 comes higher with using the suitable solvent. The percentage of initiator has a great effect on the bonding agent product also its impacts on the strain corresponding to maximum stress as with adapting the percentage of initiator can obtain the acceptable mechanicals properties that candidates our demands. 


\section{References}

1. P. D. Gilbert, Multifunctional additives for composite solid propellant, MSc Thesis, Purdue University, (2008),pp 15

2. G. S. Tussiwand, V. E. Saouma, R. Terzenbach, L. T. De Luca, Fracture mechanics of composite solid rocket propellant grains: Material testing, J. Propul. Power (2009),pp 25,60

3. P. H. Geubelle, H. M. Inglis, J. D. Kramer, J. Patel, N. C. Kumar, H. Tan, Multiscale modeling of dewetting damage in highly filled particulate composites, AIP Conf. Proc. (2008), 973, 196

4. N. Niehaus, O. Greeb, Optimization of propellant binders-Part two: Macroscopic investgation of the mechanical properties of polymers, Propellants Explos. Pyrotech. (2004), 29, 333

5. J. C. Li, Q. J. Jiao, H. Ren, D. Li, Preparation of NC-BA-RDX coating ball particles by means of layer-to-layer assembly technique, J. Solid Rocket Technol. 2008,pp 31, 247

6. T. F. Nihal, U. B. Zht, The effect of ammonium nitrate, coarse/Fine ammonium nitrate ratio, plasticizer, bonding agent, and $\mathrm{Fe} 2 \mathrm{O} 3$ content on ballistic and mechanical properties of hydroxyl terminated polybutadiene based composite propellants containing 20\% AP, J. ASTM Int. (2005), pp 2, 233

7. A. A. Ali, J. W. Zhang, G. B. Cai, Investigation of the role of aziridine bonding agents on the aging of the composite solid rocket propellant (CSRP), J. Aerosp. Pow. (2008),pp 23, 2101

8. J. Sciamareli, M. F. K. Takahashi, J. M. Teixeira, Solid polyurethane-based composite propellant: I - Influence of the bonding agent, Quim. Nova (2002), 25, 107

9. X. H. Zhang, F. Q. Zhao, H. M. Tan, Improving mechanical property of CMDB propellant containing nitramine with bonding agent, Chinese J. Explos. Propell. (2005), pp 28

10. F. Q. Zhao, W. G. Shan, S. W. Li, Review on silane coupling agents used in solid rocket motor charges and their action mechanism, Energ. Mater. (1998), pp 6, 37

11. H. Y. Zhang, Advances in low signature signal CMDB propellants, J. Solid Rocket Technol. (2000), 23, 36

12. H. X. Tang, X. L. Liu, Q. Wu, Action mechanism of special functional agents in composite solid propellant. (IV) Processability/ mechanical properties, J. Solid Rocket Technol. (2004), pp 27,193

13. Y. Wang, G. Qiu, Thermal behavior of bonding agent 1,1-(1,3-phenylenedlcarbonyl) bis-2-methyl-aziridine, J. Propul. Technol. (2001),pp 22, 258

14. Alain D. Solid Rocket Propulsion Technology. Pergamon Press, ISBN 0-08-040999-pp 7,(1993)

15. R. Brown and E. Cooke, Manufacture of Propellant Compositions and Propellant Charges, United States Patent No. 6,036,894, March, (2000) 